\title{
ESTUDO DA INFLUÊNCIA DA AGITAÇÃO NA PRODUÇÃO DE BIODIESEL POR TRANSESTERIFICAÇÃO ETÍLICA
}

\author{
E. G. LIMA ${ }^{1}$, M. B. SATIRO ${ }^{1}$, J. C. MARINHO ${ }^{1}$, M. W. N. C. CARVALHO ${ }^{1}$, A. A. CUTRIM ${ }^{2}$ \\ ${ }^{1}$ Universidade Federal de Campina Grande, Unidade Acadêmica de Engenharia Química \\ ${ }^{2}$ Universidade Federal de Campina Grande, Unidade Acadêmica de Engenharia de Petróleo \\ E-mail para contato: erigenuino@ hotmail.com
}

\begin{abstract}
RESUMO - A agitação do sistema reacional é uma das variáveis de maior influência na reação catalítica, auxiliando na dispersão do catalisador no meio reacional, consequentemente aumentando a conversão. Nessa perspectiva, visando desenvolver um estudo comparativo entre dois sistemas de produção de biodiesel, sendo eles: Sistema 1, um reator batelada sem agitação e o sistema 2, um reator com agitação magnética. Utilizando uma temperatura de $200^{\circ} \mathrm{C}$, com $2 \%$ de catalisador a base de argila impregnada com $\mathrm{MoO}_{3}$ (VNI), 4 horas de reação e como matéria-prima os óleos de soja e algodão, para ambos os sistemas. Os óleos obtidos foram analisados por cromatografia gasosa para determinação do teor de éster etílico formado e análise da viscosidade cinemática. Quando utilizou-se o sistema estático a conversão encontrada em ambos os óleos correspondeu a aproximadamente 50\%, no sistema com agitação a conversão aumenta consideravelmente alcançando valores próximos a $80 \%$.
\end{abstract}

\section{INTRODUÇÃO}

De acordo com Froehner et al. (2007), a utilização do biodiesel, como combustível substituinte ao diesel derivado de petróleo, tem apresentado grande destaque mundial, devido a sua enorme contribuição ao meio ambiente, como a redução qualitativa e quantitativa dos níveis de poluição ambiental, e por se apresentar como fonte estratégica de energia renovável. No cenário brasileiro, o seu uso pode também reduzir a dependência de importação deste combustível.

Além da grande contribuição ambiental, o biodiesel pode ser produzido a partir de diferentes fontes lipídicas, que de maneira geral, resumem-se em gordura animal e óleos vegetais degomado ou usado, tais como óleo de soja, mamona, babaçu, algodão, entre outros, descritos em trabalhos de Silva (2011).

$\mathrm{Na}$ produção de biodiesel comercial, o método mais utilizado, faz uso de catalisadores homogêneos alcalinos, como por exemplo, hidróxido de sódio $(\mathrm{NaOH})$ e potássio $(\mathrm{KOH})$, por meio da reação de transesterificação ou esterificação. $O$ uso destes catalisadores nesta reação se deve principalmente à sua elevada eficiência e baixo custo. Entretanto esses catalisadores apresentam algumas desvantagens como à dificuldade na sua reutilização, recuperação da glicerina, risco de contaminação do produto e gasto elevado de água para purificação do biodiesel. 
Com o objetivo de minimizar os principais problemas do processo homogêneo, várias pesquisas têm sido realizadas com o propósito de identificar os melhores catalisadores heterogêneos. Destaca-se que os catalisadores utilizados na rota heterogênea são facilmente removidos por um simples processo de filtração, reduzindo assim a geração de efluentes e os custos no processo, conforme estudos desenvolvidos por (Cruz, et al, 2009)

Segundo Santos et al. (2002), como catalisadores heterogêneos destaca-se as zeólitas, óxidos de metais, enzimas, resinas de troca iônica e as argilas. As argilas, por possuírem propriedades adequadas, abundância e serem de fácil manuseio, apresentam uma vasta aplicabilidade. Esses materiais apresentam elevado poder adsorvente e podem ser empregadas como peneiras moleculares; agentes descorantes e clarificantes de óleos vegetais e minerais; suportes catalíticos; agente de filtração; adsorventes de óleos em água; em reações de obtenção de biocombustíveis, entre outros empregos.

Em trabalhos de Silva (2008) é destacado que a superfície externa das argilas pode ser modificada por tratamentos químicos e/ou térmicos, os quais podem influenciar na atividade catalítica. Ressalta-se que tratamentos muito fortes podem diminuir a sua atividade podendo possivelmente destruir a estrutura cristalina da argila. É importante citar que em poucos casos as argilas são ativas na sua forma natural, necessitando, quase sempre, de tratamentos químicos baseados na sua capacidade de troca iônica.

De acordo com Costa (2009), dentre os mais diversos tipos de argilas existentes, encontra-se a vermiculita, composta por argilominerais hidratados de ferro, magnésio e alumínio do grupo das esmectitas, apresentando uma elevada capacidade de troca iônica, semelhante a algumas argilas e as zeólitas, possui um alto poder adsorvente, podendo ser utilizada em processos de remoção de contaminantes orgânicos e nas águas residuais contendo sais dissolvidos.

Desta forma, a proposta deste trabalho foi motivada com o intuito de avaliar a influência da agitação no meio reacional, verificando o desempenho de um catalisador a base de argila vermiculita impregnado com $\mathrm{MoO}_{3}$ em dois sistemas reacionais diferentes.

\section{METODOLOGIA}

\subsection{Sistema 1}

O catalisador (VNI) foi submetido ao teste reacional para verificar a eficiência do mesmo na reação de transesterificação dos óleos de soja e de algodão, utilizando um sistema estudado por Silva (2011), composto por um reator batelada de politetrafluoretileno encamisados por uma peça de aço inox sem agitação (Figura 1). As condições reacionais estudadas foram às mesmas utilizadas por Silva (2008), utilizando temperatura igual a $200^{\circ} \mathrm{C}$ com 4 horas de reação, utilizando uma razão molar óleo/álcool de 1/12 e $2 \%$ de catalisador referente à massa de óleo utilizada. 


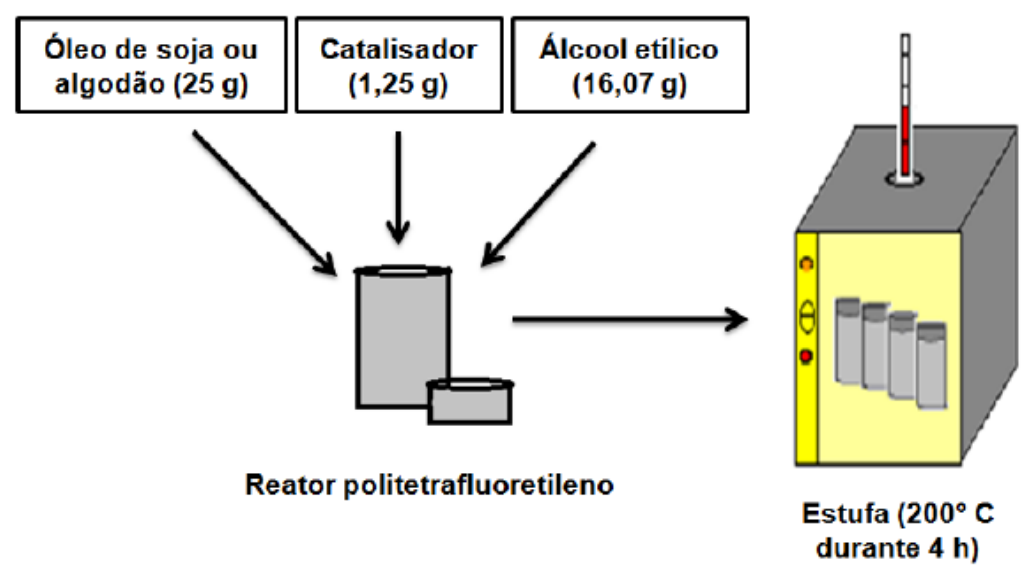

Figura 1 - Reator batelada utilizado na síntese do biodiesel

Ao término do tempo reacional, os reatores foram resfriados, posteriormente a mistura foi lavada com água deionizada aquecida a $75^{\circ} \mathrm{C} \pm 5^{\circ} \mathrm{C}$ e com o auxílio de um funil de separação ocorreu à remoção do catalisador e da glicerina formada no biodiesel. As amostras foram colocadas em beckers e levadas à estufa a temperatura de $110{ }^{\circ} \mathrm{C}$ por aproximadamente 1 hora para a completa remoção de água. Em seguida, a amostra foi armazenada em vidro âmbar e colocada em local sem umidade e luminosidade protegendo-as de uma possível degradação quando expostas a luz. Após esta etapa, o produto foi submetido às devidas caracterizações de viscosidade cinemática e teor de éster.

\subsection{Sistema 2}

O sistema reacional 2 com agitação magnética denominado Reator químico de alta pressão (Figura 2), utilizando o catalisador (VNI) nas seguintes condições: $200{ }^{\circ} \mathrm{C}, 2 \%$ de catalisador e 4 horas de reação.



Figura 2 - Reator químico de alta pressão. 
A mistura (óleo, álcool e catalisador) foi acondicionada em um reator de alta pressão em aço 316L modelo ZHM-50Ml. Essa mistura foi mantida nas mesmas condições de síntese do sistema S1 sob agitação de $666 \mathrm{rpm}$. Decorrido o tempo de reação, o produto foi resfriado, separado, lavado e devidamente armazenado para a realização das determinações de teor de éster e viscosidade cinemática.

\subsection{Viscosidade Cinemática}

Segundo Atkins e Jones (2006), a viscosidade é a resistência ao escoamento, é a propriedade dos fluidos correspondente ao transporte microscópico de quantidade de movimento por difusão molecular, ou seja, quanto maior a viscosidade, menor a velocidade em que o fluido se movimenta. A viscosidade usualmente diminui com o aumento da temperatura. A viscosidade das amostras foi determinada utilizando o viscosímetro de Cannon Fenske, este equipamento utiliza de um banho a $40^{\circ} \mathrm{C}$ com um tubo capilar de numeração 300 , a determinação da viscosidade é resultado do escoamento total do líquido presente no bulbo do tubo no capilar, multiplicado pelo tempo gasto para esse escoamento, conforme a Equação 1:

$$
V=K . t
$$

Onde: $\mathrm{K}=0,2407 \mathrm{~mm}^{2} / \mathrm{s}^{2}$, é a constante.

$\mathrm{T}$ (s) é o tempo de escoamento do líquido pelo capilar.

A viscosidade é um indicativo preliminar que demonstra a conversão em ésteres, isto é observado pela redução da viscosidade do produto obtido na síntese

\subsection{Teor de Éster}

As análises dos ésteres etílicos foram determinadas por Cromatografia em fase Gasosa. De acordo com Pelisson (2008), a Cromatografia Gasosa é uma técnica para separação e análise de misturas de substâncias voláteis. A amostra é vaporizada e introduzida em um fluxo de um gás adequado denominado de fase móvel ou gás de arraste. Este fluxo de gás com a amostra vaporizada passa por um tubo contendo a fase estacionária (coluna cromatográfica), onde ocorre à separação da mistura. Este método de análise é uma técnica analítica proposta para determinar o teor de álcool, ésteres totais e de glicerol livre e ligado.

Estas análises foram conduzidas em Cromatográfo a Gás Varian 450c com detector de ionização de chamas, coluna capilar de fase estacionária Varian Ultimetal "Select Biodiesel Glycerides + RG" $(15 \mathrm{~m} \times 0,32 \mathrm{~mm} \times 0,45 \mu \mathrm{m})$. O preparo das amostras consistiu na diluição de $50 \mathrm{mg}$ destas em $5 \mathrm{~mL}$ de n-hexano padrão UV/HPLC (Vetec P.A./A.C.S.) e posterior injeção de $1 \mu \mathrm{L}$ da solução. O padrão utilizado foi padrão interno fornecido pela Varian Inc.

\section{RESULTADOS E DISCUSSÕES}


No estudo do efeito da agitação do meio reacional, foram utilizadas as mesmas condições para ambos os sistemas, utilizando $200^{\circ} \mathrm{C}, 2 \%$ de catalisador e 4 horas de reação. Os resultados dos testes catalíticos com agitação estão descritos na Tabela 1.

Tabela 1 - Viscosidade e conversão para o sistema com agitação.

\begin{tabular}{|c|c|c|}
\hline Catalisador & Viscosidade $\left(\mathrm{mm}^{2} / \mathrm{s}\right)$ & Conversão em éster $(\%)$ \\
\hline VNI - Óleo de soja & 7,68 & 81,09 \\
\hline VNI - Óleo de algodão & 9,84 & 79,71 \\
\hline ANP & $3-6$ & 96,8 \\
\hline
\end{tabular}

Tabela 2- Viscosidade e conversão para o sistema sem agitação

\begin{tabular}{|c|c|c|}
\hline Catalisador & Viscosidade $\left(\mathrm{mm}^{2} / \mathrm{s}\right)$ & Conversão em éster $(\%)$ \\
\hline VNI - Óleo de soja & 14,66 & 41,93 \\
\hline VNI - Óleo de algodão & 14,27 & 49,81 \\
\hline ANP & $3-6$ & 96,8 \\
\hline
\end{tabular}

Pela análise da Tabela 1 pode-se observar que a agitação do meio reacional influência na reação de transesterificação, consequentemente na redução de viscosidade e conversão em éster, comparando os resultados com as normas exigidas pela ANP, verifica-se uma grande aproximação dos dados com os parâmetros exigidos pela mesma. Em estudos realizados por Marinho (2012) foi ressaltado a importância da agitação do sistema para a melhor homogeneização dos produtos reacionais. A agitação do meio reacional irá proporcionar uma maior dispersão do catalisador, possibilitando uma maior interação do catalisador com as moléculas do óleo e do álcool.

Quando utilizou-se um sistema estático com as mesmas condições a conversão encontrada com ambos os óleos correspondeu a aproximadamente $50 \%$ (Tabela 2), na análise do estudo com a agitação a conversão aumenta consideravelmente e consequentemente a viscosidade sofre um elevado decréscimo, ressaltando assim que agitação durante o processo reacional, aumenta a interação das moléculas, elevando a conversão no produto desejado.

\section{CONSIDERAÇÕES}

De acordo com os resultados encontrados na realização dos testes reacionais, observa-se que na utilização do um sistema com agitação o catalisador a base de argila impregnado com $\mathrm{MoO}_{3}$ apresentou elevada atividade aumentando a conversão consideravelmente, mostrando que a agitação tem grande influência na formação dos produtos da reação, proporcionando uma maior interação dos reagentes no processo reacional. 


\section{REFERENCIAS}

ANP - Biocombustivel. Disponivel em: http://www.anp.gov.br/?id=470. Acessado em: Fevereiro de 2012.

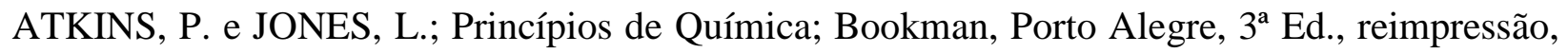
2006, pag. 256.

COSTA, G. E. L; NEUMANN, R; Transformação de Vermiculita para biotita, visando melhor refinamento via método de Rietveld para quantificação de fases: estudo de caso com a Vermiculita de Santa Luzia - PB. In XVII Jornada de Iniciação Científica - CETEM - Rio de Janeiro - 2009.

CRUZ, R. S; LOBO, I. P; FERREIRA, S. L. C; Biodiesel: Parâmetros de Qualidade e Métodos Analíticos. Quim. Nova, Vol. 32, No. 6, 1596-1608, 2009.

FROEHNER, S; LEITHOLD, J; JÚNIOR, L. F. L, Transesterificação de óleos vegetais: Caracterização por cromatografia em camada delgada e densidade. Quim. Nova, Vol. 30, No. 8, Curitiba - PR, Outubro, 2007.

MARINHO, J. C.; Biodiesel Obtido a partir do Óleo de Soja e Algodão Utilizando Argilas Pilarizadas e Impregnadas com Óxido de Molibdênio. Dissertação (Mestrado em Engenharia Química). Universidade Federal de Campina Grande - UFCG, Campina Grande - 2012.

PELISSON, L. Análise direta de mono, di e triacilglicerídeos em biodiesel por cromatografia gasosa de alta resolução: resolução ANP 42 e suas extensões. Dissertação (Mestrado em Química) - Universidade Federal de São Paulo - São Carlos, 2008.

SANTOS, C. P. F; MELO, D. M. A; MELO, M. A. F; SOBRINHO, E. V; Caracterização e usos de argilas Bentonitas e Vermiculitas para adsorção de cobre (II) em solução, Cerâmica vol.48 no. 308, São Paulo, Oct./Dec. 2002.

SILVA, A. A.; Novos catalisadores a base de argilas para a produção do Biodiesel, 167p. Tese (Doutorado em Engenharia de Processos) - Universidade Federal de Campina Grande - UFCG Campina Grande - PB, 2008.

SILVA, A. S. Avaliação de catalisadores de NiO e MoO3, suportados em MCM-41, na obtenção de biodiesel de óleo de algodão. Tese (Doutorado em engenharia de processos) - Universidade Federal de Campina Grande, Campina Grande, 2011. 